Dennis and James: Site-specific factors in green space productivity.

Ecosystem Services

Site-specific factors in the production of local urban ecosystem services: a case study of community-managed green space.

M. Dennis and P. James

School of Environment and Life Sciences, College of Science and Technology, University of Salford, The Crescent, Salford. M5 4WT.

Corresponding author: Matthew Dennis, Room 203, Cockroft Building, University of Salford, The Crescent, Salford, M5 4WT.

Phone: 01612953823

E-mail: m.dennis@salford.ac.uk 


\title{
Site-specific factors in the production of local urban ecosystem services: a case study of community-managed green space.
}

\begin{abstract}
Pockets of green space in cities can provide important ecosystem services for urban residents. As naturalistic spaces in urban areas become increasingly sparse, communities are beginning to co-manage existing incidental pockets of land towards the creation of communal natural resources. Such green commons can be productive in terms of ecosystem services through targeted management such as in the case of urban agriculture. Although some work has been done to explore the motives behind and potential benefits of informal green space management, further research is required to understand those characteristics of site management and community input which contribute to the enhancement of sitespecific ecosystem service production. A case study of ten examples of community-managed green space was undertaken to evaluate the contributory factors relating to site character and management which influenced productivity as defined by the cumulative provision of four urban-relevant ecosystem services. The analysis revealed that the level of community involvement, measured as intensity of volunteer hours, was highly instrumental in the productivity of sites. Food production also proved to be catalytic for the enhancement of ecosystem services whereas extent of vegetative cover and increasing site size were, counter-intuitively, detrimental to overall site productivity. The study therefore supports the promotion of participatory approaches to the management of ecosystems services in urban areas, particularly those which take small-scale urban agriculture as a primary practice.
\end{abstract}

\section{Introduction}

Collaborative approaches to environmental stewardship through stakeholder management of ecosystems and the ecosystem services they provide have been given increasing support (Krasny and Tidball, 2015). Public stewardship and participation in nature-based activities were highlighted in the UK National Ecosystem Assessment (UK NEA) report (2011) as significant contributors to both human and environmental health and well-being. In that report it is stated that "a key knowledge gap regarding education and ecological knowledge goods concerns the processes by which adults acquire ecological knowledge, their participation in nature-based educational activities and how knowledge acquisition is influenced by engagement with environmental settings as a form of cultural service" (UK NEA, 2011, p.83). The authors of that report also highlighted, and recommended, increasing public participation in the management of ecosystems. Community-led ecological initiatives aimed at environmental education and stewardship can go some way to bridging the disconnect that exists between humans and the environment (Miller, 2005). The promotion of environmental awareness and opportunities for positive human-nature interactions may help to reverse this trend and create more environmentally conscious communities and cities. Stakeholder involvement has likewise been promoted through international policies (CBD, 2001; MEA; 2005) which call for the appropriate decentralisation of natural resource management towards more localised and flexible stewardship of ecosystems and the services they provide. These assertions are echoed in the scientific literature where collective management of urban green commons by urban residents has been posited as one social-ecological measure that may be key in the building of more resilient cities in light of the major challenges they face (Ernstson et al., 2008; Biggs et al., 2010; Colding and Barthel, 2013). Civic ecological intervention has been promoted as an effective way of creating and preserving green infrastructure in urban areas (Krasny and Tidball, 2015). Such collaborative approaches to green space management therefore support the UK government's goal to 
promote green infrastructure in urban landscapes as outlined in the 2011 Environment White Paper (Defra, 2011).

Given these recommendations and that the actual benefits of stakeholder-led stewardship of urban spaces remain unclear, an understanding of the actual situation regarding the development and benefits of community-led ecological stewardship represents a contemporary research imperative.

\section{Participatory approaches to management of urban green commons}

Previous studies have highlighted the potential of collaboratively managed urban green space to deliver diverse benefits such as personal well-being and social capital (Hynes and Howe, 2004; Pudup, 2008; Krasny and Tidball, 2015), community cohesion (Okvat and Zautra, 2011) and crime reduction (Kuo et al., 1998). Studies have demonstrated that the stewarding of local urban nature also promotes a sense of place among communities (Stedman, 2003; ODPM, 2004; Kudryavtsev et al., 2012; Tidball and Stedman, 2013) which in turn builds on individual and community well-being.

Barthel et al., 2010 have championed community-horticulture as an important medium for the building of social-ecological memory and adaptive capacity, a theme echoed in studies into civic ecology (Krasny and Tidball, 2015). Although there is much evidence to support these claims, there is a paucity of research which examines such benefits through the lens of ecosystem services. In this regard, the unique productivity of collectively managed green space is often overlooked by local planning authorities (Francis, 1987) in favour of more familiar urban green space types such as municipal parks and nature reserves. Work has been carried out which demonstrates that stakeholder managed gardens exhibit greater biodiversity than more conventionally managed urban green space types (Orsini et al., 2014; Lin et al., 2015; Speak et al., 2015) and that biodiversity increases proportional to levels of user participation (Dennis and James, 2016). However, the benefits issuing from participatory approaches to green space management have yet to be effectively investigated as comprising discrete ecosystem services, nor the relationships between such services.

\section{Ecosystem Services in Urban Areas}

Bolund and Hunhammer (1999), in one of the earliest works on urban ecosystem services, stated that, although all people regardless of whether they live in urban or rural areas are dependent on global ecosystems, "The quality of life for urban citizens is improved by locally generated services, e.g. air quality and noise levels that cannot be improved with the help of distant ecosystems." (p. 8). Despite such locally derived benefits from urban ecosystems, the authors of the Millennium Ecosystem Assessment (2005) chose largely to ignore the urban landscape and cities are generally seen as the recipients rather than producers of ecosystem services (Krasny and Tidball, 2015). Urban areas can however harbour biodiverse habitats (Smith et al., 2006; Davies et al., 2009; Goddard et al., 2010; Cameron et al., 2012) and, through forms of social-ecological innovation and civic engagement, provide ecosystem services in the form of pollination (Strauss, 2009), food production (Saldivar and Krasny, 2004; Lawson, 2005) and education (Krasny and Tidball, 2009).

Notwithstanding the presence of these potential gains from urban nature, the majority of research into urban ecosystem services has focused on those accruing to human well-being stemming from living in proximity to green space (Kaplan, 1995; de Vries et al., 2003; Jackson, 2003; Maas et al., 2006; Maller et al., 2006) and interacting with urban nature (Bird, 
2007; Tzoulas et al., 2007; Marselle et al., 2014; Carrus et al., 2015); with larger scale studies concentrating on recreation, climate mitigation and water attenuation services (van der Ploeg and de Groot, 2010; UK NEA, 2011).

The need to evaluate trade-offs, and synergies, associated with the provision of ecosystem services has been presented as a current management imperative in social-ecological systems (MEA, 2005) and, to this end, studies on urban ecosystems services have been carried out (e.g., Nelson et al., 2009; Power, 2010; Raudsepp-Hearne et al., 2010; Haase et al., 2012; Howe et al., 2014). Such studies document relationships between services at the landscape scale, but fail to address design or management considerations contributing to the productivity of urban green space types. Therefore, a better appreciation of on-theground service production by, as well as the use and management of, green assets in urban social-ecological systems is still required.

Sites of amenity green space in urban areas have been presented as being important to urban-relevant ecosystem services (Barthel et al., 2010; Niemelä et al., 2010; Ernstson, 2013), though attempts to quantify those services are few and the mechanisms which influence the productivity of such spaces are still little understood. Furthermore, at small scales of natural resource management, such as in the case of urban green space, little is known about the influence of design and management on productivity in terms of ecosystem services. Approaches to management of these green assets are diverse, especially in the case of informally-managed spaces such as community gardens and allotments, and little is understood about the characteristics of informal approaches to urban land use which contribute to the production of ecosystem services. Although the UK NEA Synthesis Report (2011) promotes a participatory approach to natural resource management, it provides little evidence of the mechanisms by which such an approach may effectively manage ecosystem services. The benefits of initiatives involving inclusive, stakeholder-led management of urban green space have been clearly asserted in the literature (Barthel et al., 2010; Ernstson, 2013) but as yet little work has been done to articulate such benefits as specific ecosystem services. Neither has there been any attempt to identify design or management approaches which may be synergistic with the production ecosystem services related to such innovative forms of green space management. Accordingly, the need for an increase in the body of research into ecosystem services production in urban areas was one of the key findings of the UK NEA (2011).

In order to address this gap in knowledge, a case study of ten informal, community-managed green space sites, covering four discrete management approaches, in the Greater Manchester area were examined. The sites were assessed across four ecosystem services (microclimate regulation, food yield, biodiversity potential, and education and well-being) and an evaluation was carried out on the contribution made to overall productivity of case studies by selected physical and management characteristics (vegetation cover, food cultivation area, genera richness, volunteer input, and site size) of the case study sites.

\section{Study area}

The study took Manchester, Salford and Trafford, three adjoining metropolitan districts in the Greater Manchester area, as its focus. This urban zone contains multiple examples of collaboratively managed urban green space (AfSL, n.d.; Dennis and James, 2016) which stem from a strong historical prevalence of social-ecological activism (Ritvo, 2010). Ten examples 
of autonomous, stakeholder-managed green space associated with four discrete management approaches were selected for the study. Case study locations within the study area are shown in Figure 1 and site descriptions are presented in Table 1.

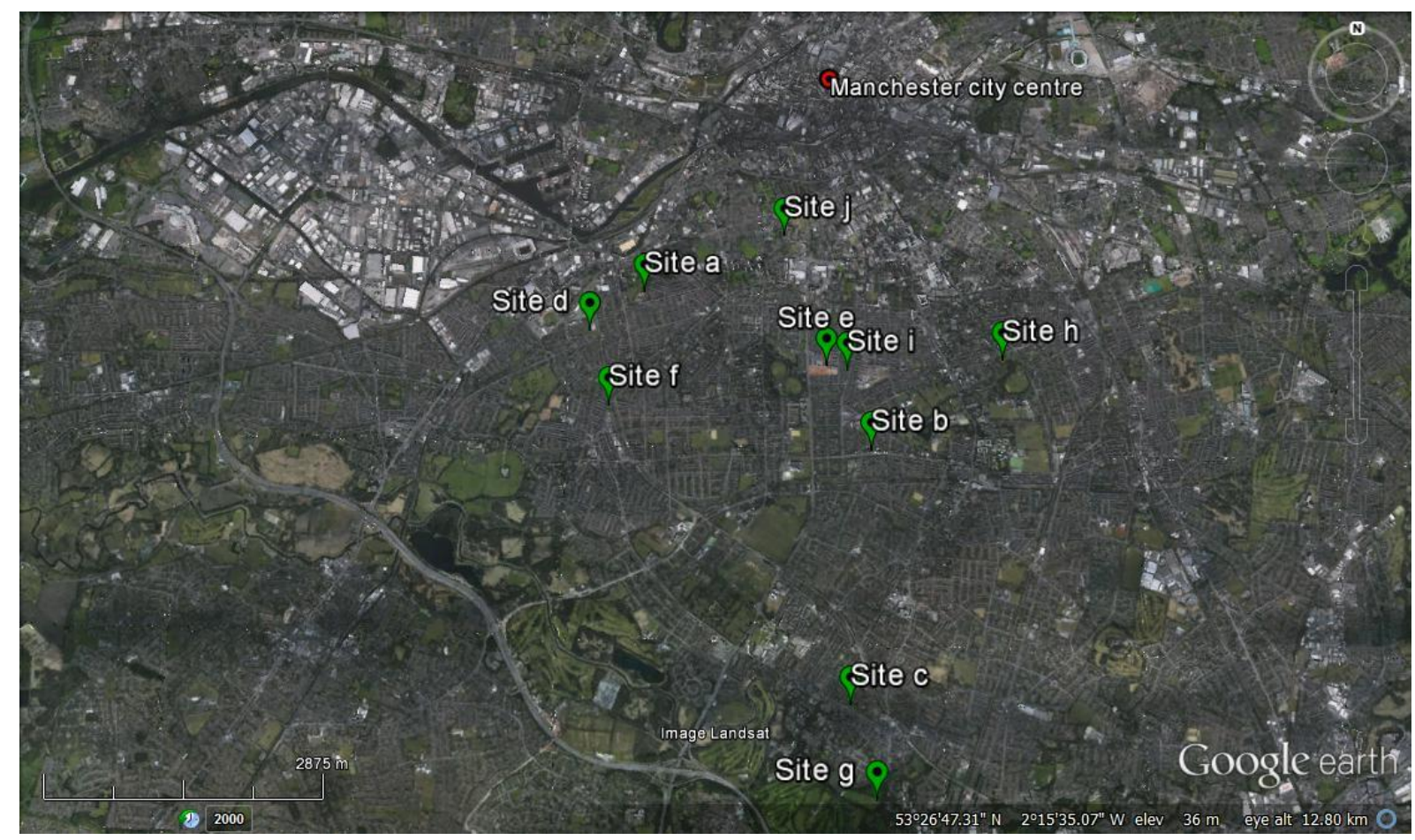

Figure 1 Location of the case study sites

Source: Google Earth 7.0. 2015. Manchester, $53^{\circ} 26^{\prime} 47.31^{\prime \prime} \mathrm{N}, 2^{\circ} 15^{\prime} 35.07^{\prime \prime} \mathrm{W}$, elevation $36 \mathrm{~m}$. [Accessed 02 January 2016]. Available from: http://www.google.com/earth/index.html

Table 1 Case study sites and descriptions

\begin{tabular}{|c|c|}
\hline Sites & Description \\
\hline$a, b, c$ (community gardens) & $\begin{array}{l}\text { Multi-functional green space in residential areas. Some } \\
\text { emphasis on food cultivation and horticulture, variety } \\
\text { of design approaches and size }\left(500 \mathrm{~m}^{2}-1500 \mathrm{~m}^{2}\right) \text {. }\end{array}$ \\
\hline$d, e, f$ (community allotments) & $\begin{array}{l}\text { Communal plots on established allotment sites under } \\
\text { collective management }\left(600 \mathrm{~m}^{2}-1000 \mathrm{~m}^{2}\right) \text {. }\end{array}$ \\
\hline$g, h$ (community orchards) & $\begin{array}{l}\text { Spaces dedicated primarily to cultivation of soft or hard } \\
\text { fruit. Occurring in extensive communal recreational } \\
\text { areas }\left(1000 \mathrm{~m}^{2}-2000 \mathrm{~m}^{2}\right) \text {. }\end{array}$ \\
\hline$i, j$ (pocket parks) & $\begin{array}{l}\text { Small }\left(<300 \mathrm{~m}^{2}\right) \text { sites subject to high levels of surface } \\
\text { sealing. Highly improvised. Innovative approaches to } \\
\text { site greening (e.g. green roofs/façades, raised bed } \\
\text { systems). }\end{array}$ \\
\hline
\end{tabular}

\section{Methods}

Sites were assessed across four urban-relevant ecosystem services as suggested in the associated literature: microclimate regulation (Bolund and Hunhammer, 1999, van der Ploeg and de Groot, 2010; UK NEA, 2011; Aubry et al., 2012) food yield (Barthel et al., 2011; UK NEA, 2011; Krasny and Tidball, 2015), biodiversity potential (Goddard et al., 2010; UK NEA, 2011; Dennis and James, 2016), and education and well-being (Hansmann et al., 2007; 
Krasny and Tidball, 2009; UK NEA, 2011). These ecosystem services were assessed individually for each case study site through field surveys and consultations.

\section{Microclimate regulation}

Microclimate regulation was evaluated using the Green Infrastructure (GI) Toolkit developed by Green Infrastructure North West in the UK. The tool provides a score based on the proportion of a given site which can be deemed as ecologically effective and is determined by the extent of both horizontal and vertical vegetative and artificial structures. The basic premise of the tool is to create a score ranging from zero to one based on the surface area cover types as well as secondary and tertiary layers (made up of structural elements such as shrubs, trees, green roofs/walls and water harvesting systems). The resulting score, ranging from 0 to 1, represents the proportion of a site which can be considered ecologically effective. For highly stratified, structurally diverse sites scores greater than 1 are possible. The tool was developed in Berlin as the Biotope Area Factor tool (Becker and Mohren, 1990) and modified by planning authorities in Sweden where it was adapted in 2001 for the Malmö Green Space Factor (Krause, 2011). The Malmö Green Space Factor was adopted almost seamlessly in the UK by Sutton and Southampton councils and subsequently modified to some degree by the North West Development Agency resulting in the development of the Green Infrastructure Toolkit (Green Infrastructure North West, 2010). Data were collected from each site through field measurements during detailed site surveys and attributing the relevant surface type designated within the Gl toolkit to that observed on-site. The data were then entered directly into the Gl toolkit work sheet.

Data were collected during site surveys which were carried out between April and September 2013. On each occasion, a single site visit was sufficient to complete the assessment.

\section{Food production}

Food yield was projected using proxy figures adapted from other studies of productive community-managed urban gardens (Vitiello and Nairn, 2009) and from UK horticultural datasets (Defra, 2013). A proxy for vegetable crop cultivation was calculated from data acquired from the Philadelphia Harvest Report of community-managed urban vegetable gardens (Vitiello and Nairn, 2009). In the case of orchards and other sites partially designated to fruit production, projected yields per square metre were calculated from the UK government Basic Horticultural Statistics dataset (Defra, 2013). Where fruit production was evident, crop yields were estimated based on whether soft or hard fruits were in cultivation. For hard fruit, average orchard yields per square metre were calculated (as mean UK commercial yields 2007 - 2011: Defra, 2013) and used as a proxy. For soft fruit, a proxy value was calculated as the mean of national soft fruit yields 2007 - 2011 (Defra, 2013). Data for food production at each site were collected simultaneously as part of the survey carried out for microclimate regulation in which each surface cover type was recorded in detail.

\section{Biodiversity potential}

The biodiversity assessment employed was developed at the University of Salford (Tzoulas and James, 2010) and focusses on vegetation structure through the use of biodiversity surrogates, Tandy's Isovist technique and the Domin scale (Sutherland, 1996). This provides a rapid assessment method of biodiversity for use in urban environments. In the assessment, the percentage cover of each type of vegetative structure (defined using categories developed by Freeman and Buck (2003)) is estimated using a method adapted from Tandy's 
Isovist technique (Westmacott and Worthington, 1994). This measure is then combined with the number of genera of vascular plants recorded to give a combined score for overall biodiversity. Although straightforward in approach the method gives accurate, comparable biodiversity measures for a variety of green space types. A fuller explanation of the background to the biological surrogates and scales used in the method as well as the rationale of the scoring system can be found in Tzoulas and James (2010). Biodiversity assessments were carried out in fair weather conditions during the summer months June to August 2013. Each site assessment for biodiversity potential was carried out as a single visit. The assessments thereby constituted a snapshot perspective, which was consistent with the evaluation of food production and microclimate regulation.

\section{Education and Well being}

Data were gathered on cultural ecosystem services through the application of selected indicators from Natural England's monitoring and evaluation protocols for the socio-cultural benefits that individuals and communities receive from interaction with quality green space (Natural England, 2014). These were Volunteer Hours and Educational Visits. Volunteer hours, relating specifically to physical activity at case study sites (as total hours month ${ }^{-1}$ ), were recorded; data relating to administration activities were not included in the analysis. The number of educational and community events which take place at each site over the course of a year was equally recorded as an additional measure of cultural ecosystem services provision following the rationale of the Natural England protocols. As such, these data, when summed, served as proxy measures for the contribution to community education and well-being provided by each site based on the Natural England protocols.

Data pertaining to education and well being were collected from site managers/project facilitators via correspondence or during site visits according to access and availability of sources. This element of data collection was therefore conducted in a more ad-hoc fashion than for other ecosystem service assessments over a period spanning March 2013 to December 2013.

\section{Measures of overall ecosystem service provision}

The relative contribution of each site to the total ecosystem service provision for the case study was calculated. Data collected from the ecosystem service assessments were standardised by site area to give a measure of site productivity (as values $100 \mathrm{~m}^{-2}$ ). Using the standardized values obtained from the ecosystem service assessments of case study sites, the contribution made by each site to the case study total for each service was calculated as a percentage. Subsequently, site percentage contribution towards each of the selected services $(n=4)$ for the case study were summed to give a measure of cumulative service provision. For each site, the resulting cumulative provision score, served to reflect the relative level of productivity of each site in the case study as a measure of service provision per unit area. This process resulted in a standardised dataset with which it was possible to explore with confidence correlations between total service provision and underlying site characteristics. The subsequent calculation of the cumulative provision score, as a grand score reflecting site productivity, provided an effectively continuous variable for use in statistical analyses of site attributes and overall performance.

\section{Data analysis}

These data were explored by evaluating synergies and trade-offs between particular site characteristics as well as the effect of those characteristics on the cumulative provision score 
of each site. In keeping with the spatially-oriented approach, all values were standardised by site area. The site characteristics used in the analysis were: food cultivation area (percentage cover), genera richness $100 \mathrm{~m}^{-2}$, volunteer hours month ${ }^{-1} 100 \mathrm{~m}^{-2}$, and percentage vegetation cover. These attributes were selected on the basis that they were all principle components of site design and each a key contributory factor in the tools used to measure individual service provision (food yield, biodiversity potential, education and well-being, and microclimate regulation respectively). In the case of vegetation cover, this characteristic was defined as the total site area where vegetative features were connected to the underlying soil substrate (as opposed to containers or raised beds for cultivation) as defined by the GI toolkit used in the microclimate regulation assessment.

Attributes which were measured as percentages all contained several scores below $20 \%$ and were therefore normalised via arc sine transformation prior to inclusion in the analysis. Given that site productivity and characteristics were measured using values standardised by site size, total site area was also included among the site attributes in the analysis as a characteristic which had bearing on overall service provision. Pearson's product-moment correlation tests and regression analyses were performed in SPSS.20.

\section{Results}

\section{Site Contributions to Service Provision.}

The cumulative provision score of each site (expressed as a percentage), broken down by individual services, is presented in Figure 2.

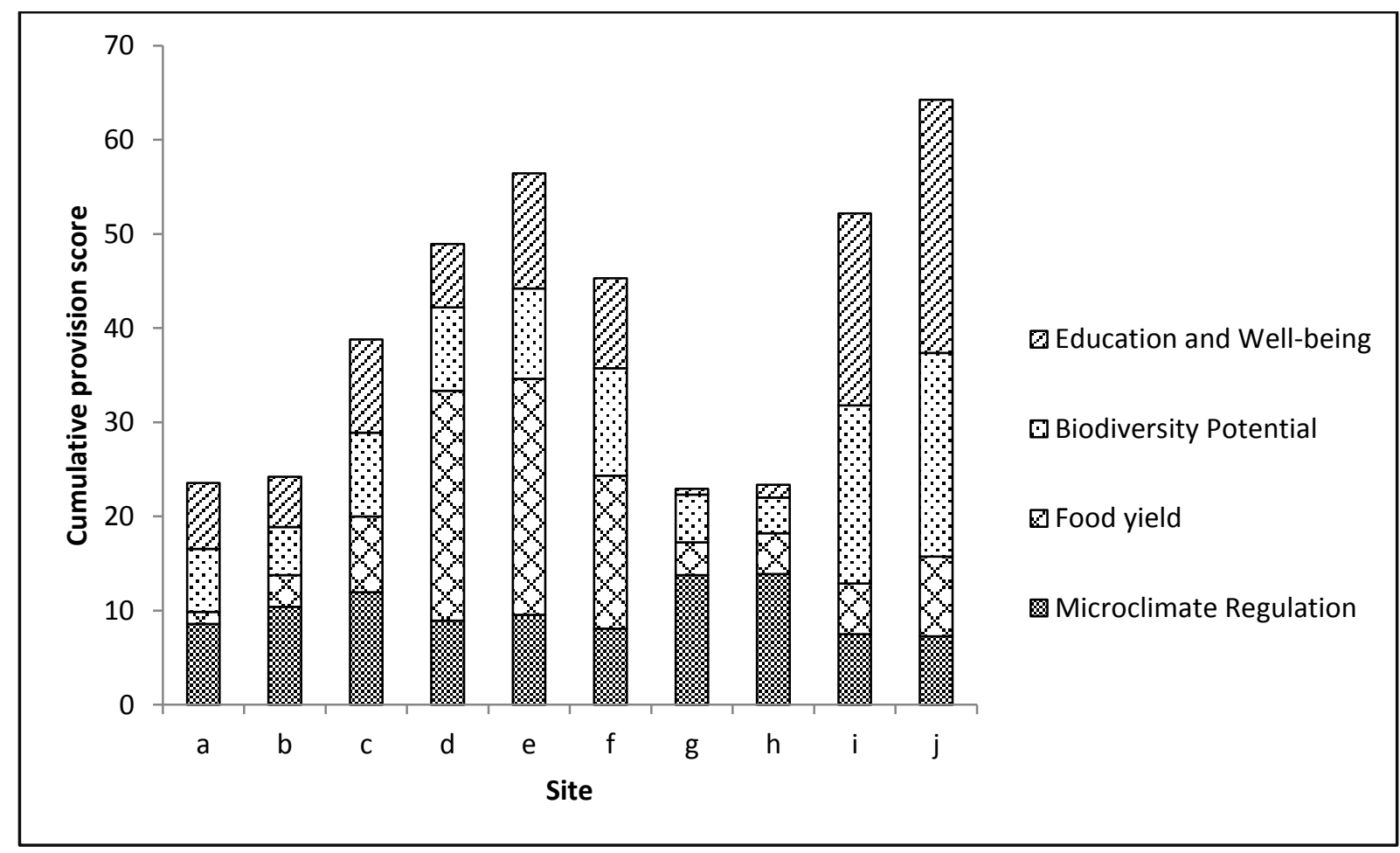

Figure 2. Site contributions to case study cumulative provision score.

\section{Relationships between site characteristics and productivity}

Correlations between site characteristics and cumulative provision score are presented in Table 2. 
Table 2. Site characteristic relationships (all parameters entered as values $100 \mathrm{~m}^{-2}$ ).

\begin{tabular}{|c|c|c|c|c|c|c|}
\hline & & $\begin{array}{c}\text { Genera } \\
\text { richness } \\
100 \mathrm{~m}^{-2}\end{array}$ & $\begin{array}{c}\begin{array}{c}\text { Volunteer } \\
\text { hours }\end{array} \\
\text { month }^{-1} \\
100 \mathrm{~m}^{-2}\end{array}$ & $\begin{array}{l}\text { Area food } \\
\text { cultivation }\end{array}$ & $\begin{array}{l}\text { Total } \\
\text { area }\end{array}$ & $\begin{array}{l}\text { Cumulative } \\
\text { provision } \\
\text { score }\end{array}$ \\
\hline \multirow[t]{3}{*}{$\begin{array}{l}\text { Vegetation } \\
\text { cover }\end{array}$} & $\begin{array}{l}\text { Pearson } \\
\text { Correlation }\end{array}$ & -0.836 & $-0.705^{\circ}$ & 0.239 & $0.659^{\circ}$ & $-0.673^{*}$ \\
\hline & Sig. (2-tailed) & 0.003 & 0.023 & 0.506 & 0.038 & 0.033 \\
\hline & $N$ & 10 & 10 & 10 & 10 & 10 \\
\hline \multirow{3}{*}{$\begin{array}{c}\text { Genera } \\
\text { richness } \\
100 \mathrm{~m}^{-2}\end{array}$} & $\begin{array}{l}\text { Pearson } \\
\text { Correlation }\end{array}$ & & $0.923^{* x}$ & -0.163 & $-0.830^{* \pi}$ & $0.771^{\star *}$ \\
\hline & Sig. (2-tailed) & & 0.000 & 0.653 & 0.003 & 0.009 \\
\hline & $\mathrm{N}$ & & 10 & 10 & 10 & 10 \\
\hline $\begin{array}{l}\text { Volunteer hours } \\
\text { month }^{-1} 100 \mathrm{~m}^{-2}\end{array}$ & $\begin{array}{c}\text { Pearson } \\
\text { Correlation }\end{array}$ & & & -0.071 & $-0.802^{x \pi}$ & $0.863^{\pi x}$ \\
\hline & Sig. (2-tailed) & & & 0.845 & 0.005 & 0.001 \\
\hline & $\mathrm{N}$ & & & 10 & 10 & 10 \\
\hline $\begin{array}{l}\text { Area food } \\
\text { cultivation }\end{array}$ & $\begin{array}{l}\text { Pearson } \\
\text { Correlation }\end{array}$ & & & & 0.036 & 0.343 \\
\hline & Sig. (2-tailed) & & & & 0.920 & 0.332 \\
\hline & $\mathrm{N}$ & & & & 10 & 10 \\
\hline Total area & $\begin{array}{c}\text { Pearson } \\
\text { Correlation }\end{array}$ & & & & & $-0.773^{* \pi}$ \\
\hline & Sig. (2-tailed) & & & & & 0.009 \\
\hline & $\mathrm{N}$ & & & & & 10 \\
\hline
\end{tabular}

** Correlation is significant at the 0.01 level (2-tailed).

* Correlation is significant at the 0.05 level (2-tailed).

Of the correlation values between site characteristics and relative to site cumulative provision score, volunteer hours month ${ }^{-1} 100 \mathrm{~m}^{-2}\left(r^{2}=0.75 ; p=0.001\right)$ exhibited the highest positive correlation with cumulative provision score. In terms of between-characteristic relationships, genera richness $100 \mathrm{~m}^{-2}$ correlated positively with volunteer hours month ${ }^{-1}$ $100 \mathrm{~m}^{-2}\left(r^{2}=0.85 ; p<0.001\right)$, and, counter-intuitively, negatively $\left(r^{2}=0.70 ; p=0.003\right)$ with percentage vegetation cover. To gain an understanding of the influence of volunteer effort on biodiversity potential a linear regression was performed with volunteer hours month ${ }^{-1}$ $100 \mathrm{~m}^{-2}$, as the predictor variable. The relationship is visualised in Figure 3. 


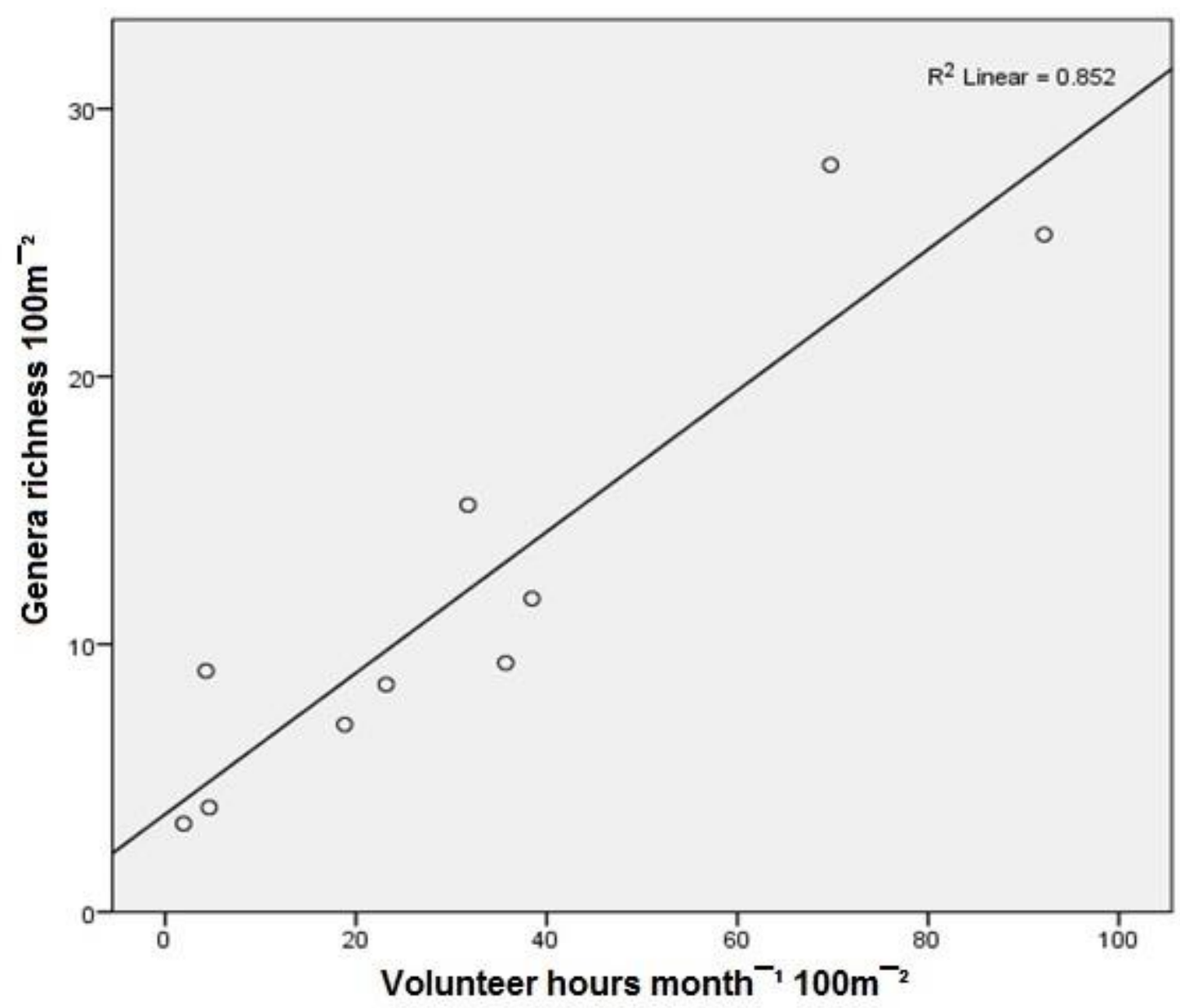

Figure 3. Volunteer effort: effect on site genera richness $100 \mathrm{~m}^{-2}(p<0.001)$.

According to the regression analysis, site volunteer input accounted for $85 \%$ of the variation in site genera richness $100 \mathrm{~m}^{-2}$, with a beta coefficient of 0.923 . Overall, the genera richness $100 \mathrm{~m}^{-2}$ score bore the greatest and most significant correlation with cumulative percentage contribution and as such appeared to be the most indicative of the site characteristics contributing to overall service provision. Volunteer hours also demonstrated considerable synergy to cumulative provision score. From these associations it was deduced, particularly given the context of sites as community managed spaces, that site output was highly influenced by human input. As such, they were to a large extent a direct result of volunteer effort, as denoted in the strong correlation observed in Table 2 between volunteer hours and site cumulative provision score (and visualised in Figure 4). 


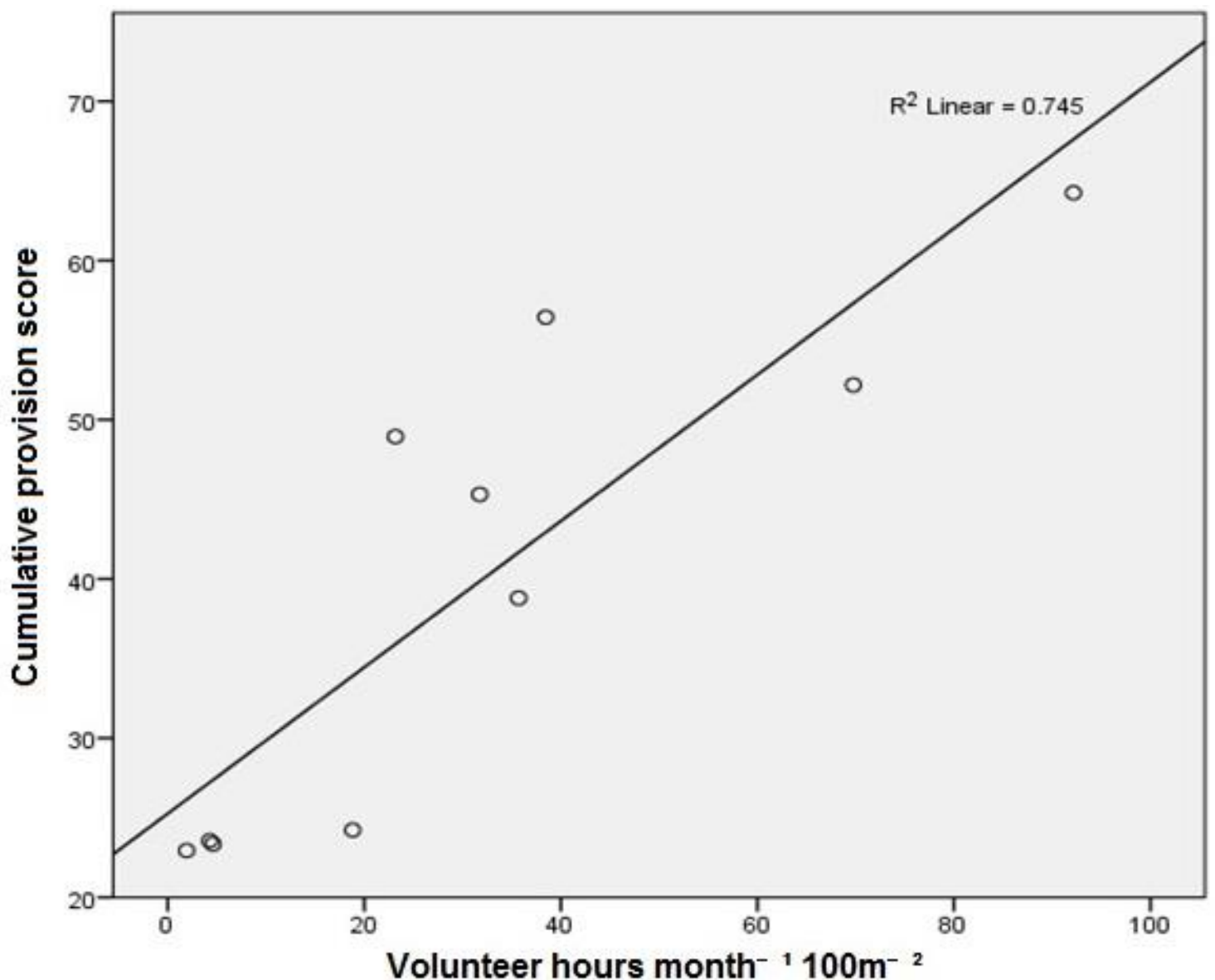

Figure 4. Regression of site volunteer effort against cumulative service provision score; $p=0.001$.

The spatial dimension of site design in particular proved to be instrumental in the efficiency of ecosystem service provision observed in the case study, site size clearly having a strong bearing on overall productivity (Figure 5 ). 


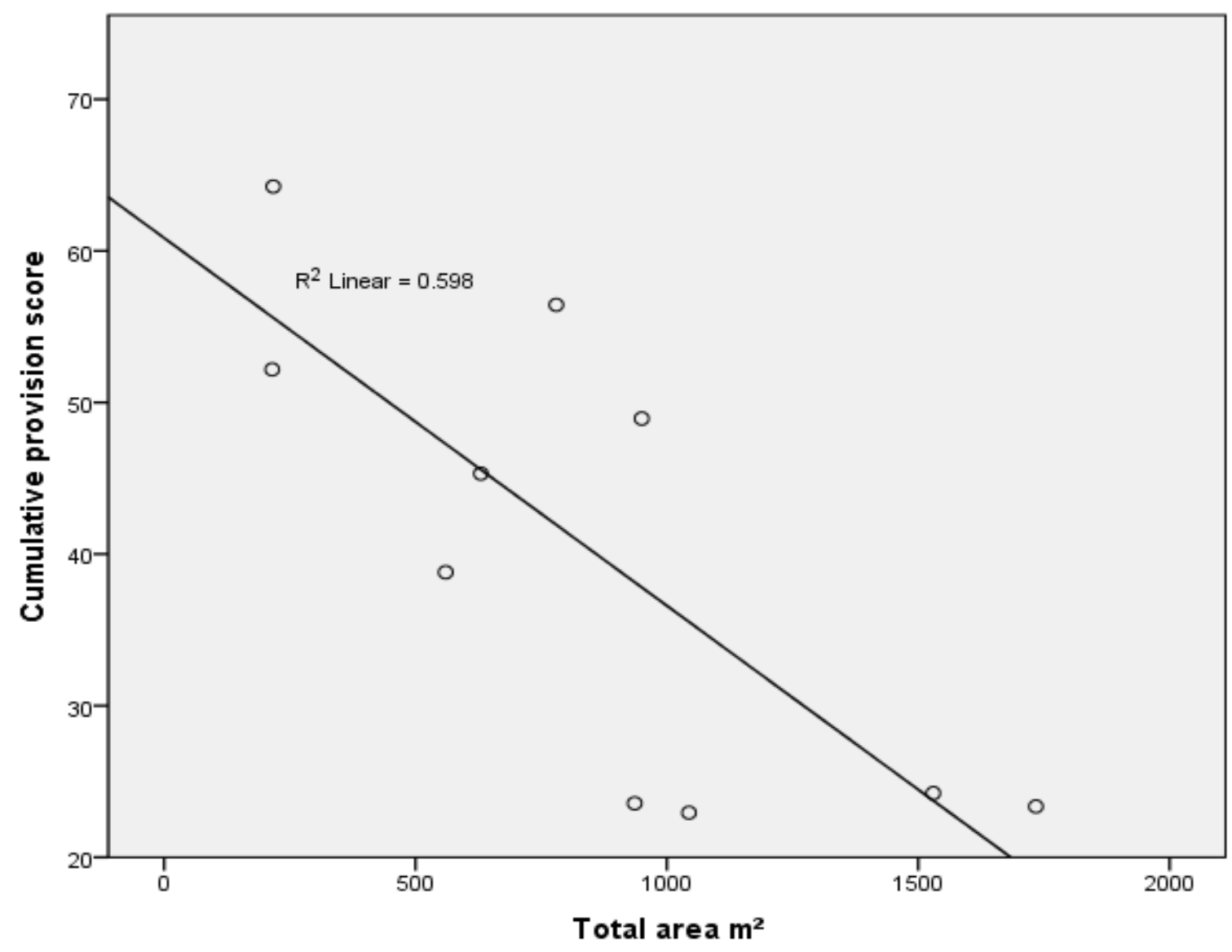

47

49

50

Figure 5. Site area and cumulative provision score regression $(p=0.009)$

In order to control for between-characteristic associations and clarify synergistic effects of each of these on overall performance, analysis was conducted, by way of multiple regression, to delineate the relative effect of site attributes on productivity. The independent variables: percentage vegetation cover, genera richness $100 \mathrm{~m}^{-2}$, volunteer hours month ${ }^{-1} 100 \mathrm{~m}^{-2}$ and percentage area cultivated for food were entered into a backwards conditional regression model (SPSS.20). The results of the regression model demonstrated that these variables were responsible for almost all of the variation observed in the overall relative performance by sites, with an $r$-squared value of $0.98(p<0.001)$. The output of the test revealed that, although genera richness $100 \mathrm{~m}^{-2}$ demonstrated a high correlation with overall performance (Table 3 ), this variable was removed from the final model $(p=0.108)$. Moreover, of the remaining variables in the final model, area of food cultivation exhibited strong partial and semi-partial correlations with cumulative provision score despite not having demonstrated significance in the Pearson's product-moment correlation analysis (Table 2). Vegetation cover exhibited a negative relationship with overall productivity. These relationships are summarised in Table 3. 


\begin{tabular}{|c|c|c|c|c|c|c|c|c|c|}
\hline \multirow{2}{*}{\multicolumn{2}{|c|}{ Model }} & \multicolumn{2}{|c|}{$\begin{array}{l}\text { Unstandardized } \\
\text { Coefficients }\end{array}$} & \multirow{2}{*}{$\begin{array}{c}\begin{array}{c}\text { Standardized } \\
\text { Coefficients }\end{array} \\
\text { Beta }\end{array}$} & \multirow[b]{2}{*}{$\mathrm{t}$} & \multirow[b]{2}{*}{ Sig. } & \multicolumn{3}{|c|}{ Correlations } \\
\hline & & $\mathrm{B}$ & $\begin{array}{l}\text { Std. } \\
\text { Error }\end{array}$ & & & & $\begin{array}{l}\text { Zero- } \\
\text { order }\end{array}$ & Partial & $\begin{array}{l}\text { Semi- } \\
\text { partial }\end{array}$ \\
\hline \multicolumn{2}{|c|}{$\begin{array}{ll}1 & \text { (Constant) }\end{array}$} & 33.511 & 6.927 & & 4.838 & 0.005 & & & \\
\hline & $\begin{array}{l}\text { Volunteer hours } \\
\text { month }^{-1} 100 \mathrm{~m}^{-2}\end{array}$ & 0.503 & 0.087 & 0.945 & 5.792 & 0.002 & 0.863 & 0.933 & 0.348 \\
\hline & $\begin{array}{l}\text { Vegetation } \\
\text { cover }\end{array}$ & -0.345 & 0.078 & -0.448 & -4.444 & 0.007 & -0.673 & -0.893 & -0.267 \\
\hline & $\begin{array}{l}\text { Genera richness } \\
100 \mathrm{~m}^{-2}\end{array}$ & -0.707 & 0.361 & -0.379 & -1.955 & 0.108 & 0.771 & -0.658 & -0.117 \\
\hline & $\begin{array}{l}\text { Area food } \\
\text { cultivation }\end{array}$ & 0.700 & 0.096 & 0.458 & 7.267 & 0.001 & 0.343 & 0.956 & 0.437 \\
\hline \multirow[t]{4}{*}{2} & (Constant) & 24.111 & 6.046 & & 3.988 & 0.007 & & & \\
\hline & $\begin{array}{l}\text { Volunteer hours } \\
\text { month }^{-1} 100 \mathrm{~m}^{-2}\end{array}$ & 0.356 & 0.053 & 0.669 & 6.745 & 0.001 & 0.863 & 0.940 & 0.492 \\
\hline & $\begin{array}{l}\text { Vegetation } \\
\text { cover }\end{array}$ & -0.261 & 0.079 & -0.340 & -3.329 & 0.016 & -0.673 & -0.805 & -0.243 \\
\hline & $\begin{array}{l}\text { Area food } \\
\text { cultivation }\end{array}$ & 0.724 & 0.116 & 0.473 & 6.246 & 0.001 & 0.343 & 0.931 & 0.455 \\
\hline
\end{tabular}

Volunteer effort exhibited the highest beta coefficient in the analysis. However, cultivation area also exhibited comparable partial and semi-partial correlation coefficients which suggested that much of the positive contribution towards overall service provision derived from genera richness $100 \mathrm{~m}^{-2}$ and volunteer activity issued from the degree of emphasis placed on food cultivation at given sites. Data on area of food cultivation was backtransformed for the purpose of interpretation. The regression equation subsequently explained that, in the case-study scenario presented here, an increase of $10 \%$ in area designated for food production led to a subsequent increase in site cumulative provision score of approximately $25 \%$. Although this interpretation defies the allocation of an absolute value to the effect of site food cultivation extent, it gives an impression of the relative influence of urban agriculture in facilitating site delivery of ecosystem services overall. In terms of community participation, an increase in volunteer effort of 1 hour $100 \mathrm{~m}^{-2}$ day $^{-1}$ led to a relative increase in cumulative provision score of $10 \%$.

\section{Discussion}

Participatory approaches to the management of common resources in cities have been posited as a route to more resilient management of urban ecosystem services (Ernstson et al., 2008; Biggs et al., 2010; Colding and Barthel, 2013). Knowledge about how such benefits are mediated or enhance by physical characteristics of sites, and site management, is however currently lacking. The investigation into such relationships described here proved to be a valid exploration, revealing that all site characteristics studied (with the exception of food cultivation area) exhibited significant correlations with at least one other characteristic and the cumulative provision score. The analysis therefore suggests that there exist both 
synergies to be exploited and trade-offs to be managed in civic approaches to green space management.

The measure of site productivity, assessed from a spatial orientation, was negatively associated with increasing site size (Figure 5), suggesting that smaller sites were more efficiently productive in terms of overall ecosystem service provision. Given that cultivation extent and volunteer effort were both highly influential towards total site product (Table 3), it can be inferred that smaller sites more readily achieve a high level of management intensity compared with much larger sites. Total volunteer input, for example, did not increase proportional to site size and, being that human and community resources are finite, larger sites clearly suffered from a lack of management intensity due to such limitations. As a result, site size was in fact negatively correlated with volunteer input per unit area, as well as with site genera richness per unit area. Social-ecological action based at small scale sites may therefore be likely to provide, from a spatial viewpoint, a more efficient return in terms of service provision than that occurring on a larger scale. This inverse site-size productivity relationship mimics the already established, counter-intuitive, inverse farm-size productivity relationship in small-holding approaches to agriculture (Alvarez, 2004), whereby smaller pockets of land apparently exhibit greater productivity. The analysis also supports conclusions from previous studies which have demonstrated a detrimental effect of greater site size on access and area-standardised measures of participation and biodiversity in collectively managed green spaces (Dennis and James, 2016). Although a multi-scale approach has been adopted in research seeking more adaptive management of urban ecosystems (Ernstson et al., 2010), little work has been done on the spatial aspect of service delivery itself, particularly from a social-ecological viewpoint. The data analysis presented herein offers insight into the on-the-ground productivity of multifunctional green commons as spatially sensitive elements in social-ecological systems, a characteristic previously ignored in the literature. Accordingly these findings apply to the ongoing debate over a land sparing versus land sharing approach towards healthy ecosystems and ecosystem service provision (Fischer et al., 2014; Stott et al., 2015), offering support to the latter model. The conclusions drawn from the analysis however were based on site areas ranging between $200 \mathrm{~m}^{2}$ to $2000 \mathrm{~m}^{2}$ and therefore it is not clear whether the relationship observed between site size and productivity holds for total land areas outside this range. Further research would be required to ascertain, for example, the minimum area required for pockets of green space to support ecosystem services or if the size-productivity association holds for much larger urban green space types.

Site area was, particularly, negatively correlated with genera richness $100 \mathrm{~m}^{-2}$ (Table 2), whereas the latter appeared to increase proportional with community input, as indicated in the analysis of volunteer effort (Figure 3). This, along with the negative relationship observed between vegetation cover and genera richness $100 \mathrm{~m}^{-2}$ (Table 2), describes a situation which differs from the usual curve seen in species-area relationships (Rice and Kelting, 1955; McGuinness, 1984) and runs contrary to general assertions in other studies into the ecology of cities as to the adverse effects of urbanisation (e.g. Helden and Leather, 2004; Thompson et al., 2004; Godefroid and Koedam, 2007; Williams et al., 2009). Accordingly, the analysis herein contradicts expectations around the effects of urbanisation on biodiversity. The implication, therefore, is that, with the concerted collective management of green commons, such deleterious effects can be subverted through the creation of bio-diverse microhabitats. Clearly, there was a linear relationship between site biodiversity and site area with the latter also being influential on volunteer input (Table 2), 
which in turn correlated with genera richness $100 \mathrm{~m}^{-2}$ (Figure 3). This presented a socialecological dynamic whereby, similar to expectations drawn from species-area dynamics in natural systems (Gotelli and Colwell, 2001), larger sites could be expected to exhibit lower species density. However the high level of anthropogenic input found at the case study sites appeared to heighten this effect, the outcome being a linear biodiversity-area relationship moderated by (human) community input. The situation in a social-ecological context is, therefore, necessarily more complex than in more naturalistic habitats. In urban areas, ecological productivity and intensification of sites in specifically urban settings is largely a function of site management (Figures 2 and 3 ), the latter also being a factor conditioned by spatial considerations (Table 2/Figure 5). Of all the case studies, the two pocket parks (sites $i$ and $j$ ), being the smallest spaces in the cohort (Table 1), appeared to exploit this dynamic to greatest effect and achieved some of the highest cumulative provision scores (Figure 2), largely due to the productive synergy observed between relatively smaller site size, and the variables volunteer hours month ${ }^{-1} 100 \mathrm{~m}^{-2}$ and genera richness $100 \mathrm{~m}^{-2}$. Conversely, due to the same processes, the relatively greater size of the community orchards in the case study (sites $g$ and $h$ ) appeared to have a detrimental effect on their overall productivity (Figure 2).

The extent of site vegetation cover had little positive impact on total service provision, and in fact correlated negatively with genera richness $100 \mathrm{~m}^{-2}$ (Table 2). This counter-intuitive relationship can be explained by the fact that sites with greater vegetative extent tended to be larger, an attribute which was associated with low volunteer input (Table 2). Due to this effect, and perhaps as a result of type-specific management practices, larger sites were less intensively cultivated and, accordingly, less diverse in terms of structure and plant genera. As such, large areas of these sites exhibited low vascular plant richness and minimal structural diversity. In this sense biodiversity levels in the study were subject to the same pressures as seen in other appraisals of urban land-use types (e.g. Niemelä, 1999; Dauber et al., 2003; Weiner et al., 2011). The difference being, however, that multi-functionality as a management approach observed in this case study, when achieved to a significant degree through volunteer input and an emphasis on crop cultivation, served not only to buffer against the homogenisation of habitat types, but to actively increase the level of biodiversity potential. The bearing of management intensity on plant genera richness $100 \mathrm{~m}^{-2}$ is echoed in the positive correlation noted between volunteer input and total provision (Figure 4).

Whereas volunteer input, genera richness and cumulative provision score all shared a strong degree of synergy in the analysis (Table 2), food cultivation extent did not correlate significantly with any other variables. However, the further exploration of factors influencing overall site productivity, carried out through multiple regression analysis summarised in Table 3 offered an alternative description of the situation. The regression analysis, controlling for confounding correlations between site characteristics, revealed that genera richness $100 \mathrm{~m}^{-2}$ was not a significant contributory factor to site productivity. Intensity of site management, measured as number of volunteer hours month ${ }^{-1} 100 \mathrm{~m}^{-2}$ and site cultivation extent for food bore the strongest influence on overall site provision. Here both variables exhibited comparable partial and semi-partial correlations with the cumulative provision score (Table 3). The analysis therefore supports the conclusion that the product of urban green space, in terms of ecosystem services, is significantly increased through community participation. Furthermore, when this participation is focussed on the practice of urban agriculture, the effect is heightened. These insights provide empirical evidence to support more conceptual work around the benefits of urban agriculture (Viljoen et al., 2005; Mawois et al., 2011; Aubry et al., 2012; Colding and Barthel, 2013), highlighting the spatial and 
management complexities which mediate the productivity of small-scale community-led agriculture. The combination of stakeholder participation and food cultivation represents an important synergy which could be harnessed to ensure the optimal delivery and continuation of ecosystem services in productive urban landscapes. That the proportion of site area covered by vegetation connected to the ground bore a negative relationship with purely naturalistic spaces in urban areas as a panacea for social-ecological well-being as previously questioned by Kowarik $(2008 ; 2011)$. Similarly, this observation contributes to the debate surrounding the trade-offs between facilitating public access to natural areas and the associated ecological degradation which is often a result (Ewert et al., 1993; Roca and Villares, 2008). The findings of this study support the idea that the increased participation of stakeholders in urban green space, although potentially leading to a decrease in ecological integrity, actually contributes significantly to the overall productivity of such spaces as ecosystem service-providing green assets. Moreover, such participation is not universally detrimental to ecological effectiveness. Particularly in areas subject to high levels of surface sealing, community-led intervention can actually add ecological value by creating small improvised pockets of green infrastructure. Given that productivity was inversely proportional to site area, the creation of such small pockets of ecologically productive land should be all the more effective. The current study therefore provides empirical evidence of the social and ecological benefits issuing from community participation in urban natural resource management. These benefits describe a positive feedback loop which occurs between community involvement in green space management, biodiversity potential, agricultural productivity and education and well-being. Further work looking at alternative ecosystem services may confirm these insights and detailed research into site management, perceived community benefit and sense of place could give insight as to the sustainability of such positive social-ecological feedbacks.

\section{Conclusions}

The study revealed that certain elements of site management and design were, individually and in combination, synergistic with overall productivity in terms of ecosystem services. Specifically, the work provides evidence to support the potential benefits of small-scale community-led agriculture in urban areas. Encouragement is also provided for the possibility of collaborative groups to generate urban-relevant ecosystem services in areas of minimal ecological interest in cities. The suggestion of an apparent inverse site-size productivity relationship in the analysis may contribute to the debate over the relative gains of land sharing versus sparing towards maximum provision of ecosystem services in the urban environment. Further work may serve to identify thresholds in such spatial trends and clarify the need to complement small-scale cultivation of urban green space with larger natural spaces in order to enhance landscape-scale ecological diversity and target alternative ecosystem services to the ones examined in this study. Notwithstanding these uncertainties, collaborative approaches to environmental stewardship in urban areas could, by enhancing positive feedbacks between management, design and participation, present an effective governance tool towards adaptive, productive social-ecological systems and provide examples for green space management in the wider landscape.

\section{References}


AfSL (Action for Sustainable Living) n.d.. Funders - See who funds our work and projects. [online] Available at: http://www.afsl.org.uk/about/funders/ (accessed 15 Jan. 2015).

Alvarez, A. 2004. Technical efficiency and farm size: a conditional analysis. Agricultural Economics. 30(3): 241-250. 2012. Urban agriculture and land use in cities: An approach with the multi-functionality and sustainability concepts in the case of Antananarivo (Madagascar). Land Use Policy. 29(2): 429-239.

Barthel, S., Folke, C. and Colding, J. 2010. Social-ecological memory in urban gardens: retaining the capacity for management of ecosystem services. Global Environmental Change. 20(2): 255-265.

Barthel, S., Sorlin, S. and Ljungkvist, J. 2011. Innovative Memory and Resilient Cities: Echoes from Ancient Constantinople. In: P.J.J. Sinclair, ed. 2010. The Urban Mind: Cultural and Environmental Dynamics.Uppsala. Uppsala University Press. Ch. 15.

Becker, G and Mohren, R. 1990. The Biotope Area Factor as an Ecological Phenomenon. Berlin. Landschaft Planen and Bauen.

Biggs, R., Westley, F. and Carpenter, S. 2010. Navigating the Back Loop: Fostering Social Innovation and Transformation in Ecosystem Management. Ecology and Society. 15(2): 9. [online] Available at: http://www.ecologyandsociety.org/vol15/iss2/art9.

Bird, W. 2007. Natural Thinking: Investigating the link between the Natural Environment, Biodiversity and Mental Health. London: Royal Society for the Protection of Birds.

Bolund, P. and Hunhammer, S. 1999. Ecosystem services in urban areas. Ecological Economics. 29: 293-301.

Cameron, R., Blanusa, T., Taylor, J., Salisbury, A., Halstead, A., Henricot, B. and Thompson, K. 2012. The domestic garden: its contribution to urban green infrastructure. Urban Forestry and Urban Greening. 11(2): 129-137

Carrus, G., Scopelliti, M., Lafortezza, R., Colangelo, G., Ferrini, F., Salbitano, F., Agrimi, M., Portoghesi, L., Semenzato, P. and Sanesi, G. 2015. Go greener, feel better? The positive effects of biodiversity on the well-being of individuals visiting urban and peri-urban green areas. Landscape and Urban Planning. 134: 221-228.

CBD (Convention on Biological Diversity). 2001. Global Biodiversity Outlook. Montreal: Secretariat of the Convention on Biological Diversity.

Colding, J. and Barthel, S. 2013. The potential of 'Urban Green Commons' in the resilience building of cities. Ecological Economics. 86: 156-166. 
Dauber, J., Hirsch, M., Simmering, D., Waldhardt, R., Otte, A. and Wolters, V. 2003. Landscape structure as an indicator of biodiversity: matrix effects on species richness. Agriculture, Ecosystems \& Environment. 98(1-3): 321-329.

Davies, Z., Fuller, R., Loram, A., Irvine, K., Sims, V. and Gaston, K. 2009. A national scale inventory of resource provision for biodiversity within domestic gardens. Biological Conservation. 142(4): 761-771.

298

Defra (Department for the Environment, Food and Rural Affairs). 2011. The natural choice: securing the value of nature. London. Defra.

Defra (Department for Environment, Food and Rural Affairs). 2013. Basic Horticultural Statistics 2013 [computer file]. London. Defra. Downloaded from: https://www.gov.uk/government/uploads/system/uploads/attachment_data/file/141609/h ort-dataset-31jul13.xls.

Dennis, M. and James, P. 2016. User participation in urban green commons: Exploring the links between access, voluntarism, biodiversity and well being. Urban Forestry \& Urban Greening. 15: 22-31.

De Vries, S., Verheij, R., Groenewegen, P. and Spreeuenberg, P. 2003. Natural environments - healthy environments? An exploratory analysis of the relationship between greenspace and health. Environment and Planning. 35: 1717-1731.

Ernstson, H. 2013. The social production of ecosystem services: A framework for studying environmental justice and ecological complexity in urbanized landscapes. Landscape and Urban Planning. 109(1): 7-17.

\section{Ernstson, H., Barthel, S., Andersson, E. and Borgström, S. 2010. Scale-Crossing Brokers and} Network Governance of Urban Ecosystem Services: The Case of Stockholm. Ecology and Society. 15(4): 28. [online] Available at:

http://www.ecologyandsociety.org/vol15/iss4/art28/

Ernstson, H., Sörlin, S. and Elmqvist, T. 2008. Social movements and ecosystem services-the role of social network structure in protecting and managing urban green areas in Stockholm. Ecology and Society. 13(2): 39. [online] URL: http://www.ecologyandsociety.org/vol13/iss2/art39/

Ewert, A., Chavez, D. and Magill, A. 1993. Culture, conflict, and communication in the wildland-urban interface. Boulder. Westview Press.

Fischer, J., Abson, D., Butsic, V., Chappell, M., Ekroos, J., Hanspach, J., Kuemmerle, T., Smith, H. and von Wehrden, H. 2014. Land Sparing Versus Land Sharing: Moving Forward. Conservation Letters. 7(3): 149-157.

Francis, M. 1987. Meanings attached to a city park and a community garden in Sacramento. Landscape Research. 12(1): 8-12. 
Freeman, C. and Buck, O. 2003. Development of an Ecological Mapping Methodology for Urban Areas in New Zealand. Landscape and Urban Planning. 63: 161-173.

341

342

343

344

345

346

347

348

349

350

351

352

353

354

355

356

357

358

359

360

361

362

363

364

365

366

367

368

369

370

371

372

373

374

375

376

377

378

379

380

381

382

383

384

385

386

387

Goddard, M. A., Dougill, A. J. and Benton, T. G. 2010. Scaling up from gardens: biodiversity conservation in urban environments. Trends in Ecology and Evolution. 25(2): 90-98.

Godefroid, S. and Koedam, N. 2007. Urban plant species patterns are highly driven by density and function of built-up areas. Landscape Ecol. 22(8): 1227-1239.

Gotelli, N. and Colwell, R. 2001. Quantifying biodiversity: procedures and pitfalls in the measurement and comparison of species richness. Ecology letters 4: 379-391.

Green Infrastructure North West. 2010. Green Infrastructure Toolkit [computer file]. Downloaded from: http://www.ginw.co.uk/resources/gi_toolkit.xls

Haase, D., Schwarz, N., Strohbach, M., Kroll, F., Seppelt, R. 2012. Synergies, Trade-offs, and Losses of Ecosystem Services in Urban Regions: an Integrated Multiscale Framework Applied to the Leipzig-Halle Region, Germany. Ecology and Society. 17(3): 22.

Hansmann, R., Hug, S. and Seeland, K. 2007. Restoration and stress relief through physical activities in forests and parks. Urban Forestry \& Urban Greening. 6(4): 213-225.

Helden, A. and Leather, S. 2004. Biodiversity on urban roundabouts-Hemiptera, management and the species-area relationship. Basic and Applied Ecology. 5(4): 367-377.

Howe, C. Suich, H., Vira, B., Mace, G. 2014. Creating win-wins from trade-offs? Ecosystem services for human well-being: A meta-analysis of ecosystem service trade-offs and synergies in the real world. Global Environmental Change. 28: 263 -275.

Hynes, H. and Howe, G. 2004. Urban horticulture in the contemporary United States: personal and community benefits. Acta Horticulturae. 643: 171-181. DOI: 10.17660/ActaHortic.2004.643.21

Jackson, L. 2003. The relationship of urban design to human health and condition. Landscape and Urban Planning. 64(4): 191-200.

Kaplan, S. 1995. The restorative benefits of nature: toward an integrative framework. Journal of Environmental Psychology. 15(3): 169-182.

Kowarik, I. 2008. On the Role of Alien Species in Urban Flora and Vegetation. In: J. Marzluff, J., Shulenberger, E., Endlicher, W., Alberti, M., Bradley, G., Ryan, C., Simon, U. and ZumBrunnen, C. eds. Urban Ecology. New York: Springer. pp.321-338.

Kowarik, I. 2011. Novel urban ecosystems, biodiversity, and conservation. Environmental Pollution. 159(8-9): 1974-1983.

Krasny, M. and Tidball, K. 2009. Community Gardens as Contexts for Science, Stewardship, and Civic Action Learning. Cities and the Environment. 2(1): 8. 
Krasny, M. and Tidball, K. 2015. Civic Ecology: Adaptation and Transformation from the Ground Up. Cambridge, MA: MIT Press.

Krause, A. 2011. GRaBS Expert Paper 6: The Green Space Factor and the Green Points System.

Kudryavtsev, A., Krasny, M. and Stedman, R. 2012. The impact of environmental education

\section{Kuo, F., Bacaicoa, M. and Sullivan, W. 1998. Transforming inner-city landscapes: trees, sense} of safety and preference. Environment and Behavior. 30(1): 28-59.

Lawson, L. 2005. City bountiful. Berkeley. University of California Press.

Lin, B., Philpott, S. and Jha, S. 2015. The future of urban agriculture and biodiversityecosystem services: challenges and next steps. Basic and Applied Ecology. 16(3): 189-201.

Maas, J., Verheij, R., Groenewegen, P., de Vries, S. and Spreeuwenberg, P. 2006. Green space, urbanity, and health: how strong is the relation? Journal of Epidemiology and Community Health. 60(7): 587-592.

Maller, C., Townsend, M., Pryor, A. and Brown, P. 2006. Healthy nature, healthy people: 'contact with nature' as an upstream health promotion intervention for populations. Health Promotion International. 21(1): 45-54.

Marselle, M., Irvine, K. and Warber, S. 2014. Examining Group Walks in Nature and Multiple Aspects of Well-Being: A Large-Scale Study. Ecopsychology. 6(3): 134-147.

Mawois, M., Aubry, C. and Le Bail, M. 2011. Can farmers extend their cultivation areas in urban agriculture? A contribution from agronomic analysis of market gardening systems around Mahajanga (Madagascar). Land Use Policy. 28(2): 434-445.

McGuinness, K. 1984. Species-area curves. Biological Reviews. 59(3): 423-440.

MEA (Millennium Ecosystem Assessment). 2005. Ecosystems and Human Well-being: Health Synthesis. Washington, DC: Island Press.

Miller, J. 2005. Biodiversity conservation and the extinction of experience. Trends in Ecology \& Evolution. 20(8): 430-434.

Natural England. 2014. Indicator: S\&E06_S: Number of volunteer hours on NIA activity. Available at: http://nia.naturalengland.org.uk/protocols/S\&E06_S.pdf (accessed 14 September 2015).

Nelson, E., Mendoza, G., Regetz, J., Polasky, S., Heather Tallis, H., Cameron, D., Chan, K., Daily, G., Goldstein, J., Kareiva, P., Eric Lonsdorf, E., Naidoo, R., Ricketts, T. and Shaw, M. 2009. Modeling Multiple Ecosystem Services, Biodiversity Conservation, Commodity Production, and Trade-offs at Landscape Scales. Frontiers in Ecology and the Environment. 7(1): 4-11. 
480

Niemelä, J. 1999. Ecology and urban planning. Biodiversity and Conservation 8: 119-131.

Niemelä, J., Saarela, S., Söderman, T., Kopperoinen, L., Yli-Pelkonen, V., Väre, S. and Kotze, D. 2010. Using the ecosystem services approach for better planning and conservation of urban green spaces: a Finland case study. Biodiversity Conservation. 19(11): 3225-3243.

ODPM (Office of the Deputy Prime Minister). 2004. Creating Sustainable Communities: Greening the Gateway. London. ODPM.

Okvat, H. and Zautra, A. 2011. Community gardening: a parsimonious path to individual, community, and environmental resilience. American Journal of Community Psychology. 47(3-4): 374-387.

Orsini, F., Gasperi, D., Marchetti, L., Piovene, C., Draghetti, S., Ramazzotti, S., Bazzocchi, G. and Gianquinto, G. 2014. Exploring the production capacity of rooftop gardens (RTGs) in urban agriculture: the potential impact on food and nutrition security, biodiversity and other ecosystem services in the city of Bologna. Food Security. 6(6): 781-792.

Power, A. 2010. Ecosystem services and agriculture: tradeoffs and synergies. Philosophical Transactions of the Royal Society: Biological Sciences. 365(1554): 2959-2971.

Pudup, M. 2008. It takes a garden: cultivating citizen-subjects in organized garden projects. Geoforum. 39(3): 1228-1240.

Raudsepp-Hearne, C., Peterson, G. and Bennett, E. 2010. Ecosystem service bundles for analyzing trade-offs in diverse landscapes. Proceedings of the National Academy of Sciences. 107(11): 5242-5247.

Rice, E. and Kelting, R. 1955. The Species-Area Curve. Ecology. 36(1): 7 - 11.

Ritvo, H. 2010. The Dawn of Green: Manchester, Thirlmere and Modern Environmentalism. Chicago: University of Chicago Press.

Roca, E. and Villares, M. 2008. Public perceptions for evaluating beach quality in urban and semi-natural environments. Ocean \& Coastal Management. 51(4): 314-329.

Saldivar, L. and Krasny, M. 2004. Culturing community development, neighborhood open space, and civic agriculture: The case of Latino community gardens in New York City. Agriculture and Human Values. 21(4): 399-412.

Smith, R., Thompson, K., Hodgson, J., Warren, P. and Gaston, K. 2006. Urban domestic gardens (IX): composition and richness of the vascular plant flora, and implications for native biodiversity. Biological Conservation 129(3): 312-322.

Speak, A., Mizgajski, A. and Borysiak, J. 2015. Allotment gardens and parks: provision of ecosystem services with an emphasis on biodiversity. Urban Forestry \& Urban Greening. http://dx.doi.org/10.1016/j.ufug.2015.07.007 
Stedman, R. C. 2003. Sense of place and forest science: toward a program of quantitative research. Forest Science. 49: 822-829.

Stott, I., Soga, M., Inger, R. and Gaston, K. 2015. Land sparing is crucial for urban ecosystem services. Frontiers in Ecology and the Environment. 13(7): 387-393.

Strauss, E., 2009. Urban pollinators and community gardens. Cities and the Environment. 2 (1): 1.

Sutherland W. Ed. 1996. Ecological census techniques: a handbook. Cambridge. Cambridge University Press.

Thompson, K., Hodgson, J., Smith, R., Warren, P. and Gaston, K. 2004. Urban domestic gardens (III): Composition and diversity of lawn floras. Journal of Vegetation Science. 15(3): 373-378.

Tidball, K. and Stedman, R. 2013. Positive dependency and virtuous cycles: from resource dependence to resilience in urban social-ecological systems. Ecological Economics. 86: 292299.

Tzoulas, K., and James, P. 2010. Making Biodiversity Measures Accessible to Non-Specialists: An Innovative Method for Rapid Assessment of Urban Biodiversity. Urban Ecosystems. 13: 113-127.

Tzoulas, K., Korpela, K., Venn, S., Yli-Pelkonen, V., Kaźmierczak, A., Niemelä, J. and James, P. 2007. Promoting ecosystem and human health in urban areas using Green Infrastructure: a literature review. Landscape and Urban Planning. 81(3): 167-178.

UK NEA (United Kingdom National Ecosystem Assessment). 2011. UK National Ecosystem Assessment: Understanding nature's value to society. London. UK NEA.

Van der Ploeg, S. and de Groot, R. 2010. The TEEB Valuation Database - a searchable database of 1310 estimates of monetary values of ecosystem services. Wageningen. The Netherlands. Foundation for Sustainable Development.

Viljoen, A., Bohn, K. and Howe, J. 2005. Continuous productive urban landscapes. Oxford. Architectural Press.

Vitiello, D. and Nairn, M. 2009. Community Gardening in Pennsylvania. 2008 Harvest Report. [online] Philadelphia: University of Pennsylvania. Available at: https://docs.google.com/viewer?a=v\&pid=sites\&srcid=ZGVmYXVsdGRvbWFpbnxoYXJ2ZXNO cmVwb3J0c2IOZXxneDozYjA2ZDZjM2M2YmUyYTYw [Accessed 5 Sep. 2013].

Weiner, C., Werner, M., Linsenmair, K. and Blüthgen, N. 2011. Land use intensity in grasslands: Changes in biodiversity, species composition and specialisation in flower visitor networks. Basic and Applied Ecology. 12(4): 292-299.

Westmacott, R and Worthington, T. 1994. Agricultural landscapes: a third look. Northampton. Countryside Commission. 
534 Williams, N., Schwartz, M., Vesk, P., McCarthy, M., Hahs, A., Clemants, S., Corlett, R., 535 Duncan, R., Norton, B., Thompson, K. and McDonnell, M. 2009. A conceptual framework for 536 predicting the effects of urban environments on floras. Journal of Ecology. 97(1): 4-9.

537

538

539 